\title{
Correction: Correction: Patients' experiences of remote communication after pacemaker implant: The NORDLAND study
}

\section{The PLOS ONE Staff}

There is an error in the Correction published on July 5, 2019. The third author's name is incorrect in the citation. The publisher apologizes for this error.

The correct citation is: Catalan-Matamoros D, Lopez-Villegas A, Lappegard KT, LopezLiria R (2019) Patients' experiences of remote communication after pacemaker implant: The NORDLAND study. PLoS ONE 14(6): e0218521. https://doi.org/10.1371/journal.pone. 0218521.

\section{References}

1. Catalan-Matamoros D, Lopez-Villegas A, Tore-Lappegard K, Lopez-Liria R (2019) Patients' experiences of remote communication after pacemaker implant: The NORDLAND study. PLoS ONE 14(6): e0218521. https://doi.org/10.1371/journal.pone.0218521 PMID: 31220146

2. Catalan-Matamoros D, Lopez-Villegas A, Tore-Lappegard K, Lopez-Liria R (2019) Correction: Patients' experiences of remote communication after pacemaker implant: The NORDLAND study. PLoS ONE 14(7): e0219584. https://doi.org/10.1371/journal.pone.0219584 PMID: 31276574

\section{G OPEN ACCESS}

Citation: The PLOS ONEStaff (2019) Correction: Correction: Patients' experiences of remote communication after pacemaker implant: The NORDLAND study. PLOS ONE 14(7): e0220828. https://doi.org/10.1371/journal.pone.0220828

Published: July 31, 2019

Copyright: ๑ 2019 The PLOS ONE Staff. This is an open access article distributed under the terms of the Creative Commons Attribution License, which permits unrestricted use, distribution, and reproduction in any medium, provided the original author and source are credited. 